\title{
As Novas Configurações Utilizadas Pelo Controle Nas Organizações
}

\section{The New Settings Used By The Control In The Organizations}

\author{
Fátima Regina Ney Matos ${ }^{1}$, Diego de Queiroz Machado ${ }^{2}$
}

\author{
${ }^{1}$ Instituto Superior Miguel Torga, ISMT, Portugal \\ ${ }^{2}$ Universidade Federal do Ceará, UFC, Brasil \\ Correspondência: Fátima Regina Ney Matos. Endereço: Av. Roberto Freire, 2184, Capim Macio CEP 59082902, \\ Natal, RN, Brasil. E-mail: fneymatos@globo.com
}

Recebido: 15 de dezembro de 2016 Aceito: 12 de março de 2017 Publicado: 01 de novembro de 2017

DOI: http://dx.doi.org/10.21714/1679-18272017v15n1.p37-45

\begin{abstract}
Resumo
O homem, grande pilar de sustentação das organizações, vem gradativamente sofrendo um processo de esmagamento. Sob o impulso de numerosos conflitos, o design das relações empregador-empregado está se transformando e o trabalhador vem perdendo cada vez mais o controle sobre os meios de produção frente às novas tecnologias. Neste ensaio, procurar-se-á identificar o impacto do processo destas transformações organizacionais a partir da modernização tecnológica sobre a organização do trabalho e como a introdução de novas tecnologias vem modificando as formas de controle mais comuns nas empresas. O processo de modernização tecnológica trouxe efeitos colaterais como insegurança, incerteza, cansaço, temor ao desemprego, vigilância mais violenta, haja vista que passa a ser feita por sofisticados mecanismos, conseguidos através da pressão emocional e introjeção de medos gerais a situações aversivas (desemprego, queda do poder aquisitivo, autoimagem negativa, perda de status, entre outras). Adaptando-se à época vigente, os detentores do poder desenvolvem novas e mais sofisticadas estratégias de controle. Neste sentido, os potenciais abusos do controle pelos grupos dominantes são subestimados, pois as novas roupagens utilizadas pelo controle nas organizações empresariais são disfarçadas pelo aparato tecnológico.
\end{abstract}

Palavras-chave: Organização do trabalho; novas tecnologias; controle.

\section{Abstract}

The man, a great pillar of support organizations, is gradually undergoing a process of crushing. Under the impetus of numerous conflicts, the design of employer-employee relationships is turning and the worker is losing more and more control over the means of production in the face of new technologies. In this essay will seek to identify the impact of these organizational transformation process from the technological modernization of work organization and the introduction of new technology has been changing the most common forms of control in companies. The process of technological modernization has brought about side effects such as insecurity, uncertainty, fatigue, fear of unemployment, more violent vigilance, since it is made by sophisticated mechanisms, achieved through emotional pressure and introjection of general fears to aversive situations (unemployment, loss of purchasing power, negative self-image, loss of status, among others). Adapting to the current era, power holders develop new and more sophisticated control strategies. In this sense, the potential abuse of control by the dominant groups are underestimated, because the new clothing used for control in business organizations are disguised by the technological apparatus.

Keywords: Organization of work; new technologies; control.

\section{Esta obra está licenciada sob uma Licença Creative Commons Attribution 3.0.}

\section{Introdução}

O rápido crescimento econômico e a expansão do comércio internacional no período pós Segunda Guerra Mundial levaram à reestruturação das relações entre as empresas em escala global. As organizações procuraram se adaptar ao processo de modernização através da introdução de inovações tecnológicas no processo produtivo, promovendo a reestruturação interna com base na definição de novos produtos, no redesenho organizacional e nas mudanças e aperfeiçoamento das linhas de produção existentes, objetivando atender as demandas de um 
mercado globalizado.

O homem, grande pilar de sustentação das organizações, vem gradativamente sofrendo um processo de esmagamento. Sob o impulso de numerosos conflitos, o design das relações empregador-empregado está se transformando e o trabalhador vem perdendo cada vez mais o controle sobre os meios de produção frente às novas tecnologias.

Estudiosos do processo de trabalho como Braverman (1987), Burawoy (1979) e Edwards (1979) consideram que os padrões históricos que estruturam o contexto geral do poder modificaram-se do controle simples e direto, baseado na vigilância e nas práticas disciplinares foucaultianas; para um controle técnico baseado na dominação do empregado pela máquina. Este processo passa pelo controle burocrático - modelo weberiano de dominação pelas regras - e chega à atualidade, com as inovações tecnológicas facilitando a centralização do processo de produção e aumentando o controle sobre os empregados. Este aspecto certamente atrai o interesse dos empresários, que sempre buscam novas estratégias e táticas para ampliar a acumulação do capital, mesmo que estas possam obscurecer o discernimento dos trabalhadores.

A tecnologia, principalmente a tecnologia da informação, está fornecendo material necessário e suficiente para a criação de uma nova economia, informacional e em rede.

Sem dúvida, informação e conhecimentos sempre foram elementos cruciais no crescimento da
economia, e a evolução da tecnologia determinou em grande parte a capacidade produtiva da
sociedade e os padrões de vida, bem como formas sociais de organização econômica.
Porém... estamos testemunhando a emergência de um novo paradigma tecnológico organizado
em torno de novas tecnologias da informação, mais flexíveis e poderosas que possibilitam que
a própria informação se torne produto do processo produtivo. Os produtos das novas
indústrias de tecnologia da informação são dispositivos de processamento de informações ou
o próprio processamento das informações... desse modo, agem sobre todos os domínios da
atividade humana e possibilitam o estabelecimento de conexões infinitas entre diferentes
domínios, assim como entre os elementos e agentes de tais atividades. Surge uma economia
em rede profundamente interdependente que se torna cada vez mais capaz de aplicar seu
progresso em tecnologia, conhecimentos e administração na própria tecnologia,
conhecimentos e eficiência, considerando as condições corretas de transformações
organizacionais e institucionais igualmente drásticas. (CASTELLS, 1999, p.119-120).

Neste ensaio, procurar-se-á identificar o impacto do processo destas transformações organizacionais a partir da modernização tecnológica sobre a organização do trabalho e como a introdução de novas tecnologias vem modificando as formas de controle mais comuns nas empresas.

\section{Breves Reflexões Filosóficas}

Na cosmogonia grega, a partir do Caos surgiram o Céu e a Terra, que deram origem à raça dos Titãs, a qual pertenciam Saturno e Réia, pais de Júpiter ou Zeus. Dentre os filhos de Júpiter, encontrava-se Vulcano, arquiteto, ferreiro, armeiro, construtor de carros e o artista de todas as obras do Olimpo. (BULFINCH, 1999), ou seja, a habilidade nas artes e produções já era praticada no mundo dos deuses.

$\mathrm{Na}$ Antiguidade clássica, o cosmos era composto por três poderes criativos: physis, a natureza; týche, o acaso e téchne, a habilidade nas artes e produções. De acordo com Oliveira (2002), a physis apresentava um caráter divino e representava o fundamento do ser no universo, a téchne era vista como inferior ao conhecimento da natureza e muitas vezes, o seu uso era punido através da týche, como pode-se observar nos artefatos criados por Dédalo. Dédalo era um artífice muito habilidoso, porém muitas de suas invenções foram mal utilizadas, haja vista a construção do labirinto para o rei Minos e a fabricação das asas com penas e cera que utilizou para fugir da prisão na qual foi posto pelo próprio Minos e que causaram a morte de seu filho Ícaro. Sempre que procurava utilizar a téchne para imitar a physis, a týche intervinha para mostrar ao homem o seu papel.

Em relação ao trabalho e a técnica, Aristóteles (1988) já identificava nas tarefas mais técnicas a redução dos fatores aleatórios ao mínimo possível; nas mais mecânicas o maior desgaste físico nos obreiros; nas mais servis uma maior utilização do corpo e nas mais ignóbeis a demanda de um mínimo de inteligência.

Durante grande parte do medievo, a mentalidade das classes dominantes foi contrária à técnica; a ferramenta, o instrumento, os aspectos técnicos do trabalho surgem na literatura ou na arte apenas como símbolos (LE GOFF, 2005), embora a técnica seja uma ação que implica o trabalho do homem sobre o homem, uma perpétua aprendizagem que começou no princípio dos tempos. (BRAUDEL, 2005).

No domínio técnico, o medo da 'novidade' agiu como força antiprogressista. De acordo com Le Goff (2005, p. 194), "inovar era uma monstruosidade, um pecado. Colocava em perigo o equilíbrio econômico, social e mental" 
embora Braudel (2005) considere que tenha acontecido, muitas vezes de modo imperceptível ou ignorado, uma pré-revolução industrial:

Uma acumulação de descobertas, de progressos técnicos, alguns espetaculares, outros quase microscópicos: as diversas engrenagens, as rodas dentadas, as cadeias de transmissão articuladas, o "genial sistema de biela-manivela", o volante que cria a regularidade do movimento, os laminadores, a maquinaria cada vez mais complexa das minas. E tantas outras inovações: tear para malha, para fabricar fitas (chamados teares de barra), processos químicos... É durante a segunda metade do século XVIII que se fazem as primeiras tentativas para adaptar a fins industriais os tornos, os berbequins, os mandris, ferramentas há muito conhecidas. É também nesta altura que se anuncia a automatização dos movimentos da tecelagem e da fiação, decisiva para a decolagem da economia inglesa. (BRAUDEL, 2005, p. 338).

Considerando o contexto acima, a palavra tecnologia é, então, originária do grego - techne e logos. Techne no sentido de artefato, de alguma coisa esculpida e logos como pensamento, razão, estudo de algo. Tecnologia significa então "conhecimento sistemático transformado em, ou manifestado em, instrumentos que devem ser aplicados às necessidades humanas". (TORNATZKI; FLEISCHER, 1990, p.15), embora apenas a partir da Revolução Industrial tenha ganho uma conotação mais valorativa.

Em relação ao trabalho, a tecnologia deveria estar a serviço da humanidade, procurando promover o seu bem estar físico, emocional e social; liberando o homem para o que Masi (2000) chama de 'ócio criativo', patrocinador das ideias inovadoras.

A tecnologia, até o momento, não libertou o homem do trabalho. Kurtz (1996, p. 5) observa, inclusive, que "a jornada de trabalho diminuiu numa proporção muito menor do que o aumento correspondente de produtividade" e, de acordo com Antunes (1999, p. 204) "a jornada pode até reduzir-se, enquanto o ritmo se intensifica", alimentado pelas inovações tecnológicas que possibilitam a maior exploração, fragmentação e controle da classe trabalhadora.

A preocupação com as implicações advindas do processo de modernização das empresas e a forma como os trabalhadores percebem e interpretam as práticas de trabalho, passam a ser elementos importantes para a compreensão e conseqüente discussão acerca da influência da tecnologia nas formas de poder, dominação e controle existentes nas organizações.

\section{Reflexões Acerca Do Poder E Das Relações De Dominação}

A existência de relações de poder e de dominação ocorre apenas nas inter-relações humanas, haja vista que o poder se manifesta e "passa a existir entre os homens quando eles agem juntos, e desaparece no instante em que eles se dispersam" (ARENDT, 2000, p.212).

Muito cedo o poder manifesta-se na vida humana, embora sem uma identificação clara, sem dizer a que veio. Surge sorrateiramente, proporcionando uma sensação de bem-estar e de felicidade, fazendo-se necessário.

A principal artimanha do poder é imiscuir-se sem ser percebido, de modo disfarçado e carregado de subterfúgios. Muito mais que mostrar-se, o poder utiliza disfarces. De acordo com Foucault (1985, p.83), "uma tática do poder é mascarar uma parte importante de si mesmo [...] estando seu sucesso na proporção daquilo que consegue ocultar".

É possível que deva-se a essa característica de mascaramento a dificuldade para "escrever a história do poder. [...] A história da teoria política e da Sociologia é em parte uma história de interminável desacordo sobre como o poder e a autoridade devem ser conceptualizados e como se relacionam entre si." ( LUKES, 1980, p. 823).

Neste aspecto, o conceito de poder é extremamente embaraçoso, pois é "demasiado vago ou ambíguo, permite explicar por demais facilmente um número grande demais de problemas. Sobretudo, é um conceito difícil de esclarecer, pois sua imprecisão e as contradições que levanta não advém da incerteza do vocabulário, mas da ambigüidade dos próprios fatos." (CROZIER, 1983, p. 19)

Desde a antiguidade, o estudo do poder desperta o interesse dos pensadores, a começar por Aristóteles.

Mandar e obedecer são condições não somente inevitáveis mas também convenientes. Alguns seres, com efeito, desde a hora de seu nascimento são marcados para ser mandados ou para mandar, e há muitas espécies de mandantes e mandados (a autoridade é melhor quando é exercida sobre súditos melhores; por exemplo, mandar num ser humano é melhor que mandar num animal selvagem; a obra é melhor quando executada por auxiliares melhores, e onde um homem manda e outro obedece pode-se dizer que houve mais obra), pois em todas as coisas compostas, onde uma pluralidade de partes, seja contínua ou descontínua, é combinada para constituir um todo 
único, sempre se verá alguém que manda e alguém que obedece, e esta peculiaridade dos seres vivos se acha presente neles como uma decorrência da natureza em seu todo, pois mesmo onde não há vida existe um princípio dominante, como no caso da harmonia musical. (ARISTÓTELES, 1988, p. 19).

Os séculos XVI e XVII foram pródigos em autores que procuraram conceituar o poder e suas manifestações, principalmente em relação ao aspecto dos sistemas políticos, sendo Nicolau Maquiavel, provavelmente, o mais influente dos pensadores que teorizaram sobre o assunto. Seu livro $O$ Príncipe, publicado em 1532, ainda hoje é considerado um manual para os que pretendem não só conquistar, mas manter posições de poder. A força e a atualidade dos ensinamentos contidos no livro, possivelmente, devem-se a perspicácia de Maquiavel em fazer da prática uma teoria, por meio da observação do comportamento dos grandes dirigentes da História.

O exercício do poder que Maquiavel ensina para um 'príncipe' assemelha-se a um dos corolários sobre o poder apresentados por Foucault (1985, p.90): "as relações de poder são, ao mesmo tempo, intencionais e não subjetivas. [...] são atravessadas de fora a fora por um cálculo: não há poder que se exerça sem uma série de miras e objetivos". E, para que um 'príncipe' atinja e conserve seus objetivos e miras deve considerar que "os meios que empregar serão sempre julgados honrosos e louvados por todos, porque o vulgo é levado pela aparência e pelos resultados dos fatos consumados, e o mundo é constituído pelo vulgo [...]." (MAQUIAVEL, 1979, p. 75).

Pensador influente no século XVII, Bacon (1979) desenvolveu a máxima "Saber é poder". No aforismo III do Novum Organun, afirma que "ciência e poder do homem coincidem, uma vez que, sendo a causa ignorada, frustra-se o efeito. [...]" (BACON, 1979, p. 13). Após pelo menos quatro séculos Foucault $(1985 ; 1998)$ também procurou mostrar que poder e saber estão intimamente relacionados. Roberto Machado (1998), reconhecido estudioso da obra e das idéias de Foucault, na introdução da Microfisica do Poder diz que "o fundamental da análise é que saber e poder se implicam mutuamente: não há relação de poder sem constituição de um campo de saber, como também, reciprocamente, todo saber constitui novas relações de poder".

Outro grande pensador do século XVII que procurou analisar as formas de poder foi Thomas Hobbes, em sua obra Leviatã ou Matéria, Forma e Poder de um Estado Eclesiástico e Civil. De acordo com Hobbes (1979, p. 53), "o poder de um homem (universalmente considerado) consiste nos meios de que presentemente dispõe para obter qualquer visível bem futuro". Considerava também que "o valor de um homem, tal como o de todas as outras coisas, é seu preço; isto é, tanto quanto seria dado pelo uso de seu poder." (HOBBES, 1979, p. 54).

Mais recentemente, no início do século XX, Max Weber diferenciou poder e dominação. Poder significando "toda probabilidade de impor a própria vontade numa relação social, mesmo contra resistências, seja qual for o fundamento dessa probabilidade" (WEBER, 2000, p. 33) e dominação ("autoridade") como "a probabilidade de encontrar obediência a uma ordem de determinado conteúdo, entre determinadas pessoas indicáveis." (WEBER, 2000, p.33).

As relações de dominação não dependem exclusivamente de meios econômicos. Para Weber (2000), estas ocorrem fundamentadas em diferentes motivos, seja por costume, por fins afetivos, por interesses materiais ou por motivos ideais.

A natureza desses motivos determina em amplo grau o tipo de dominação. [...] Em regra, entram nessas relações também outros motivos - afetivos ou racionais referentes a valores. Em casos extracotidianos, estes podem ser os únicos decisivos. No cotidiano, essas e outras relações são dominadas pelo costume e, além disso, por interesses materiais e racionais referentes a fins. Mas nem o costume ou a situação de interesses, nem os motivos puramente afetivos ou racionais referentes a valores da vinculação poderiam constituir fundamentos confiáveis de uma dominação. Normalmente, junta-se a esses fatores outro elemento: a crença na legitimidade. (WEBER, 2000, p. 139).

A crença na legitimidade possivelmente está relacionada à ideologia vigente, ou seja, são percebidas como legítimas as relações de dominação que estão introjetadas como corretas, como socialmente aceitas. Dominação também entendida como:

[...] uma propriedade estrutural da relação de poder que reflecte a assimetria fundamental dos recursos sobre os quais os actores podem se apoiar nas suas combinações mútuas. Esta dominação, contudo, não se exerce sempre no mesmo sentido (é por natureza reversível), e, sobretudo, tem necessidade, para a sua própria manutenção, do jogo das relações de poder. A dominação não é, portanto, contraditória com o poder, é uma das suas condições de exercício e só pode reconstituir-se através dele. (FRIEDBERG, 1993, p. 255).

Observa-se, portanto, que ao longo dos séculos, o poder tem se utilizado de estratégias de dominação 
crescentemente sofisticadas, sendo fluido, volátil, móvel, mutante e peça fundamental em um jogo onde os atores são vencidos ou vencedores, de acordo com as contingências, os interesses e as vontades dos dominadores.

\section{A Organização Da Produção E Do Trabalho E As Configurações Do Controle}

Tirarás dela (da terra) com trabalhos penosos o teu sustento todos os dias de tua vida. Ela te produzirá espinhos e abrolhos, e tu comerás a erva da terra. Comerás o teu pão com o suor do teu rosto, até que voltes à terra de que foste tirado; porque és pó, e em pó te hás de tornar. (GÊNESIS, 3; 17-19).

No aspecto de uma maldição bíblica, o trabalho atingiu seu apogeu na Revolução Industrial, o grande processo de transformações socioeconômicas iniciado na Inglaterra a partir de 1750, através do qual as ferramentas simples foram substituídas pelas novas máquinas.

A inovação tecnológica - máquina a vapor, tear mecânico - veio separar o homem dos meios de produção, colocando-o em lugares feios e sujos por até dezesseis horas diárias. Para Marx (1982, p. 370):

[...] a atuação simultânea de grande número de trabalhadores, no mesmo local, ou, se quiser, no mesmo campo de atividade, para produzir a mesma espécie de mercadoria sob o comando do mesmo capitalista, constitui, histórica e logicamente, o ponto de partida da produção capitalista.

No início do sistema capitalista de produção, observou-se a emergência da indústria artesanal e, posteriormente, da manufatura. Era o capital procurando criar condições satisfatórias para o aumento da produtividade. A manufatura desenvolveu-se entre o século XVI até o último terço do século XVII e distinguiu-se do artesanato, sobretudo nos aspectos quantitativos, tendo em vista que passou a ocupar um contingente maior de trabalhadores.

No período do artesanato, os trabalhadores desenvolviam uma destreza especial, uma habilidade para realizar diferentes partes da tarefa. Na manufatura, já não era exigida dos trabalhadores nenhuma destreza especial, embora, em ambas, "o trabalhador se sirva da ferramenta; na fábrica, (o trabalhador) serve à máquina" (MARX, 1982, p. 483).

A contribuição do operário que opera na indústria mecanizada é (tipicamente) de um serviçal, de um assistente cuja obrigação é manter seu ritmo afinado ao do processo da máquina e auxiliar, manipulando corretamente, os pontos onde o processo da máquina seja incompleto. Seu trabalho suplementa o processo da máquina em vez de fazer uso dela. Ao contrário, o processo da máquina é que se utiliza do operário (VEBLEN apud MARCUSE, 1999, p. 78).

Como Marx, outros estudiosos começaram a perceber que, embora as máquinas pudessem se tornar instrumentos de libertação do homem ao trabalho, estava ocorrendo o contrário. "Até as medidas destinadas a facilitar o trabalho se tornam meio de tortura, pois a máquina, em vez de libertar o trabalhador do trabalho, despoja o trabalho de todo o interesse". (MARX, 1982, p. 483).

Lafargue (1980, p. 17) observou que "à medida que a máquina se aperfeiçoa e despacha o trabalho do homem com uma rapidez e uma precisão incessantemente crescentes, o operário, em vez de prolongar o seu repouso proporcionalmente, redobra de ardor, como se quisesse rivalizar com a máquina".

Em 1930, Keynes (1995) já acreditava que "no prazo de pouquíssimos anos, poderemos estar em condições de desempenhar todas as atividades dos setores agrícolas, mineiro e manufatureiro gastando um quarto da energia humana que estávamos acostumados a gastar".

Prevendo o impacto da inovação tecnológica, Arendt (1987, p. 13) acreditava que "dentro de algumas décadas provavelmente (a inovação tecnológica) esvaziará as fábricas e libertará a humanidade do seu fardo mais antigo e natural, o fardo do trabalho e da sujeição à necessidade".

A Revolução Industrial constituiu-se no marco inicial do sistema de produção mecanizada. Foi uma "revolução capitalista, pois não foram as inovações técnicas que criaram o capitalismo, mas o capital investido nas manufaturas da Idade Média que levou à introdução da máquina-ferramenta e desenvolveu o sistema fabril" (SROUR, 1998, p. 13). A Revolução Industrial propiciou a mudança da ênfase dada ao homem como detentor da força de trabalho e dos meios de produção para a preocupação com o uso de máquinas e equipamentos, objetivando a intensificação da produção e demonstrando o interesse, por parte do capital, em acelerar o processo de apropriação do valor excedente criado pelo trabalhador.

A apropriação do valor criado pelo trabalhador tende a ser conseguida por meio do prolongamento da jornada de trabalho, da divisão do trabalho, do processo de produção baseado na cooperação e no uso de tecnologias. (SEGNINI. 1986).

Ao longo do tempo, o capital buscou obter, através da adoção de tecnologias, o aumento da produção e o 
controle da influência exercida sobre os trabalhadores. O desenvolvimento de novas tecnologias, seja de base técnica ou organizacional, impõe a busca por novas estratégias de controle, em função da necessidade do capital de manter o domínio sobre os fatores de produção.

Há duas amplas áreas de dificuldade num sistema econômico capitalista que têm de ser negociadas com sucesso para que esse sistema permaneça viável. A primeira advém das qualidades anárquicas dos mercados de fixação de preços, e a segunda deriva da necessidade de exercer suficiente controle sobre o emprego da força de trabalho para garantir a adição de valor na produção e, portanto, lucros positivos para o maior número possível de capitalistas. (HARVEY, 1994, p.117-118).

Novas formas de controle surgem como resultado do processo de modernização tecnológica e da necessidade do capital de criar mecanismos de controle adaptados aos emergentes paradigmas da organização da produção e do trabalho.

\section{Da Revolução Industrial À Emergência Do Paradigma Da Flexibilidade}

Precursoras da moderna 'organização', as guildas medievais "eram caracterizadas por estruturas de status de tarefas contínuas, [...] diferindo os superiores dos subordinados meramente em termos de maior domínio sobre as regras e maior habilidade, conhecimento e experiência na produção" (OFFE, 1976, p.25).

A partir da Revolução Industrial, com o advento da tecnologia aplicada à produção, as habilidades foram se fragmentando e se tornando mais especializadas. As estratégias de controle centralizaram o poder através da vigilância. Nas fábricas, segundo Foucault (1987, p. 122), "à medida que se concentram as forças de produção, o importante é tirar delas o máximo de vantagens e neutralizar seus inconvenientes (roubos, interrupções do trabalho, agitações e 'cabalas'), proteger os materiais e dominar as forças de trabalho".

$\mathrm{O}$ trabalhador, porém, começou a perceber que tinha algum controle a sua disposição para exercer o poder, tanto para desafiar quanto para reproduzir a estrutura formal da organização, principalmente através da formação de redes informais de comunicação, que de acordo com Mulgan apud Castells (1999, p.109), "são criadas não apenas para comunicar, mas para ganhar posições, para melhorar a comunicação".

Os comportamentos que desafiavam a estrutura formal da organização chamaram a atenção de F.W. Taylor e nasceu a Escola de Administração Científica que, de acordo com Braverman (1987) e Lipietz (1991), procurou substituir os métodos empíricos por métodos científicos, objetivando uniformizar e padronizar as atividades dos trabalhadores de maneira que o capitalista pudesse ter o controle, ou seja, o completo domínio sobre os operários.

Em síntese, Mattoso (1996) demonstra que a dissociação do processo de trabalho das qualificações dos trabalhadores, a separação entre a execução e a concepção do trabalho e o uso do monopólio sobre o conhecimento para controlar os distintos passos do processo de trabalho e seu modo de execução, resumem os pressupostos tayloristas. A função 'controle' no taylorismo adquiriu dimensões sem precedentes.

Henry Ford, no início do século XX, colocou o ser humano sob um controle quase absoluto, haja vista que fez uso de um processo que movimentava as peças a cada estação de trabalho, obrigando os trabalhadores a permanecer no mesmo local durante toda a jornada diária (linha de montagem). No modelo fordista, o controle exercido sobre os trabalhadores expressava-se através da fragmentação de especializações, da rígida estrutura organizacional, da centralização de informações, da quantidade de peças produzidas, da nítida separação entre supervisores e executores e da repartição regular do valor agregado. O controle ocorria basicamente pela excessiva especialização do trabalhador.

A partir da década de 1960, o modelo fordista começou a entrar em crise. As causas podem ser encontradas na "elevação do nível de instrução geral e da consciência de si dos coletivos dos trabalhadores, bem como a aspiração universal à realização pessoal e à dignidade no trabalho" (LIPIETZ, 1991, p.42). De acordo com Harvey (1994, p. 135), estava se tornando "cada vez mais evidente a incapacidade do fordismo e do keynesianismo de conter as contradições inerentes ao capitalismo".

A partir de meados de 1970, as indústrias começaram a vivenciar o que Mattoso (1996) chamou de uma nova revolução industrial. Este período caracterizou-se por intensas inovações técnicas e organizacionais, bem como pelas mudanças nas relações de trabalho. As empresas começaram a buscar novos padrões e modelos de organizações e este processo de modificações estruturais na produção ficou conhecido como movimento de reestruturação produtiva, que tende a dar origem a um novo formato de acumulação chamado de flexível, enxuto, modelo japonês, entre outras terminologias.

As empresas passaram a instituir novas filosofias gerenciais e técnicas de produção com o intuito de se adaptar às novas exigências do mercado. Entretanto, sempre procurando não perder o controle sobre o trabalhador. $\mathrm{O}$ 
controle passa a assumir novas configurações, afastando-se da forma tradicional caracterizada pela vigilância direta de supervisores, tendendo a ser expresso através do aumento da concentração do trabalhador na execução das atividades desenvolvidas, vigilância por parte dos próprios colegas de trabalho, ritmo de produção ditado pelas máquinas e intensificação do trabalho.

\section{O Movimento De Reestruturação Produtiva E O Controle}

O movimento de reestruturação produtiva surge como resposta à inadequação do paradigma taylorista-fordista aos padrões internacionais de produtividade e de qualidade, elementos básicos de competitividade no novo cenário econômico mundial. Para se tornarem mais competitivas, as empresas tendem a buscar novas tecnologias e processos de trabalho que assegurem a continuidade do fluxo produtivo e a manutenção da relação de subordinação do trabalho ao capital.

O marco orientador deste movimento é o modelo japonês de produção, conhecido como toyotismo. Para Coriat (1988), este modelo consiste na redefinição dos princípios de organização do trabalho em direção à recomposição das tarefas em um contexto marcado predominantemente pela automação e conseqüente controle automático de produção. De acordo com Silva (1991), o controle também é exercido a partir da inserção de elementos como o enriquecimento de cargos e o envolvimento dos trabalhadores.

Barnett apud Whebber (1997) afirma que, no processo de reestruturação produtiva, a tecnologia é associada à utilização de técnicas e procedimentos relacionados à informação e a automação. Classifica a tecnologia a partir de quatro categorias de análise: hardware técnico (configuração específica de máquinas, equipamentos e dispositivos); conhecimento (científico, habilidades técnicas, talento, criatividade, cultura geral, educação formal); organização (combinação de meios pelos quais são gerenciados o hardware e o conhecimento organizacional) e produto (resultante da interdependência dos três componentes anteriores).

Coriat (1988) e Schmitz; Carvalho (1988) retratam a tendência do uso da tecnologia no interior do ambiente fabril como mais um recurso para minimizar o tempo na execução de toda e qualquer atividade, bem como para ampliar, através de meios eletrônicos, o controle exercido sobre o processo produtivo e os agentes da produção. O processo de modernização tecnológica contribuirá para que o controle venha associado à busca do capital pela maximização do seu domínio sobre o trabalho e a produção. (PAGÉS et al., 1994).

Salermo (1994) elaborou uma classificação das possíveis inovações organizacionais em curso nas indústrias. São elas: mudanças nas relações entre as empresas, que ocorrem através de acordos cooperativos, compartilhamentos de projetos e de capacidade produtiva, aumento de subcontratação, entre outras; mudanças na organização geral da empresa que decorrem da redução das estruturas divisionais e funcionais clássicas, ou seja, as mudanças se dão através do abrandamento dos níveis hierárquicos, da redivisão das áreas de competência, da quebra de divisões funcionais e integração de áreas; mudanças na organização da produção que buscam a redução do tempo de atravessamento, aumento do giro de capital e redução de estoques e mudanças na organização do trabalho que indicam uma tendência ao abandono das noções de tarefa e de posto de trabalho, instituídas na organização clássica, em favor de várias formas de polivalência.

\section{Considerações Finais}

O processo de modernização tecnológica trouxe efeitos colaterais como insegurança, incerteza, cansaço, temor ao desemprego, vigilância mais violenta, haja vista que passa a ser feita por sofisticados mecanismos, conseguidos através da pressão emocional e introjeção de medos gerais a situações aversivas (desemprego, queda do poder aquisitivo, auto-imagem negativa, perda de status, entre outras).

A tecnologia deixa de ser percebida como uma das grandes expressões da criatividade humana
e passa a ser tomada como uma espécie de nova divindade a que se cultua. A eficiência deixa
se ser identificada com a capacidade que têm os seres humanos de pensar, de imaginar, de
arriscar-se na atividade criadora para reduzir-se ao mero cumprimento, preciso e pontual, das
ordens que vêm de cima. (FREIRE, 1982, p. 83).

Como ressalta Motta (1986, p. 65), a acumulação de capital no período manufatureiro que acelerou o desenvolvimento tecnológico, também tornou a subordinação do trabalho ao capital mais sutil e complexa. Passou a tratar de dupla subordinação, ou seja, de subordinação no aspecto técnico (transferência do trabalho para a máquina) e de subordinação no aspecto organizacional (maior subordinação ao quadro administrativo). $\mathrm{O}$ controle transforma-se em repressão. Administrar passou a ser "vigiar e punir" (FOUCAULT, 1987).

Apesar das lutas operárias, da elaboração de leis sociais sobre o trabalho, do aumento da concorrência e da complexidade dos contextos e das operações organizacionais, poucas e insignificantes mudanças ocorreram nas relações de controle entre empregador-empregado.

Adaptando-se à época vigente, os detentores do poder desenvolvem novas e mais sofisticadas estratégias de 
controle. Raros estudos são realizados sobre os (des)caminhos que a alta gerência usa, 'por trás dos bastidores', para fortalecer a sua posição e o seu controle, por meio da modelagem da legitimidade, dos valores, da tecnologia e da informação.

O advento da "era tecnológica" é carregado de um sentido ideológico que leva as pessoas a "crer que têm a felicidade de viver nos melhores tempos jamais desfrutados pela humanidade" [...] pois "a sociedade capaz de criar as estupendas máquinas e aparelhos atualmente existentes, desconhecidos e jamais sonhados pelos homens de outrora, não pode deixar de ser certamente melhor do que qualquer outra precedente." (PINTO, 2005, p. 41).

Neste sentido, os potenciais abusos do controle pelos grupos dominantes são subestimados, pois as novas roupagens utilizadas pelo controle nas organizações empresariais são disfarçadas pelo aparato tecnológico.

\section{Referências}

ANTUNES, R. Os sentidos do trabalho - ensaio sobre a afirmação e a negação do trabalho. São Paulo: Bontempo Editorial, 1999.

ARENDT, H. A Condição Humana. Rio de Janeiro: Forense, 2000.

ARISTÓTELES. Política. 2a ed. Brasília: Editora UnB, 1988.

BACON, F. Novum Organun. São Paulo: Abril Cultural, 1979. (Coleção Os Pensadores).

BRAUDEL, F. Civilização material, economia e capitalismo séculos XV-XVIII. $3^{\text {a }}$ tiragem. São Paulo: Martins Fontes, 2005.

BRAVERMAN, H, Trabalho e Capital Monopolista: a degradação do trabalho o século XXI. Rio de Janeiro: Editora Guanabara, 1987.

BULFINCH, T. O Livro de Ouro da Mitologia - Histórias de Deuses e Heróis. $4^{\mathrm{a}}$ ed. Rio de Janeiro: Ediouro, 1999.

BURAWOY, M. Manufacturing consent. Chicago: Chicago University Press, 1979.

CASTELLS, M. A sociedade em rede - A era da informação: economia, sociedade e cultura. v. 1. São Paulo: Paz e Terra, 1999.

CORIAT, B. A revolução dos robôs: o impacto sócio-econômico da automação. São Paulo: Busca Vida, 1988.

CROZIER, M. A Sociedade Bloqueada. Brasília, DF: Editora UnB, 1983.

EDWARDS, R. Contest terrain. New York: Basic Books, 1979.

FOUCAULT, M. História da Sexualidade 1: a vontade de saber. Rio de Janeiro: Edições Graal, 1985.

Microfísica do Poder. Rio de Janeiro: Edições Graal Ltda., 1998.

. Vigiar e Punir. Petrópolis: Vozes, 1987.

FREIRE, P. Ação cultural para a liberdade e outros escritos. $6^{\text {a }}$ ed. Rio de Janeiro: Paz e Terra, 1982.

FRIEDBERG, E. O Poder e a Regra - Dinâmicas da Acção Organizada. Lisboa: Instituto Piaget, 1993. (Coleção Epistemologia e Sociedade).

GÊNESIS. Bíblia Sagrada. São Paulo: Editora Ave Maria, 1984.

HARVEY. D. Condição pós-moderna - uma pesquisa sobre as origens da mudança cultural. São Paulo: Edições Loyola, 1994.

HOBBES, T. Leviatã ou Matéria, forma e poder de um estado eclesiástico e civil. São Paulo: Abril Cultural, 1979. (Coleção Os Pensadores).

KEYNES, J. M. Um novo mundo é possível (Conferência proferida em Madri em junho de 1930). Folha de São Paulo, 19/07/1995, p. 15-22.

KURTZ, R. O torpor do capitalismo. Folha de São Paulo, 11/02/1996, p.5-14.

LAFARGUE, P. O Direito à Preguiça. São Paulo: Kairós, 1980.

LE GOFF, J. A civilização do ocidente medieval. Bauru, SP: Edusc, 2005.

LIPIETZ, A. Audácia: uma alternativa para o século XXI. São Paulo: Nobel, 1991.

LUKES, S. Poder e Autoridade. In: BOTTOMORE, T.; NISBET, R. História da Análise Sociológica. Rio de Janeiro: Zahar Editores, 1980. 
MAQUIAVEL, N. O Príncipe. $2^{a}$ ed. São Paulo: Abril Cultural, 1979. (Coleção Os Pensadores).

MARCUSE, H. Tecnologia, Guerra e Fascismo. São Paulo: Unesp, 1999.

MARX, K. O Capital (Crítica da Economia Política). Livro 1, Volume 1 - O Processo de Produção do Capital. São Paulo: DIFEL, 1982.

MASI, D. O Ócio Criativo. São Paulo: Editora Sextante, 2000.

MATTOSO, J. (Org.) A desordem do trabalho. São Paulo: Atlas, 1996.

MOTTA, F. C. P. Organização e poder: empresa, Estado e escola. São Paulo: Atlas, 1986.

OFFE, C. Industry and inequality. Londres: Edward Arnold, 1976.

OLIVEIRA, B. J. Francis Bacon e a fundamentação da ciência como tecnologia. Belo Horizonte: Editora da UFMG, 2002.

PAGÉS, M. et al. O poder das organizações. São Paulo: Atlas, 1987.

PINTO, Á. V. O Conceito de Tecnologia. Volume 1. Rio de Janeiro: Contraponto, 2005.

SALERMO, M. S. Trabalho e organização na empresa industrial integrada e flexível. In: BRUNO, L.; SACCARDO, C. Organização, trabalho e tecnologia. São Paulo: Atlas, 1986.

SCHMITZ, H.; CARVALHO, R.(org.). Automação, competitividade e trabalho: a experiência internacional. São Paulo: Hucitec, 1988.

SEGNINI, L. R. Taylorismo: uma análise crítica. In: BRUNO, L.; SACCARDO, C. Organização, trabalho e tecnologia. São Paulo: Atlas, 1986.

SILVA, E. B. Refazendo a fábrica fordista. São Paulo: Hucitec, 1991.

SROUR R. H. Poder, Cultura e Ética nas Organizações. Rio de Janeiro: Campus, 1998.

TORNATZKI, L. G.; FLEISCHER, M. The Process of Technological Innovation. Lexington: Lexington Books, 1990.

WEBER, M. Economia e Sociedade: fundamentos da sociologia compreensiva. Brasília: Editora da Universidade de Brasília, 2000.

WHEBBER, P. Os impactos das novas tecnologias na gestão de recursos humanos. Dissertação de Mestrado. Natal: PPGA/CCSA/UFRN, 1997. 